\title{
God becomes beautiful ... in mathematics
}

Author:
Volker Kessler ${ }^{1,2}$
Affiliation:
${ }^{1}$ Department of Philosophy,
Practical and Systematic
Theology, University of
South Africa, South Africa
'2Akademie für christliche
Führungskräfte, Germany
Corresponding author:
Volker Kessler,
volker.kessler@me.com
Dates:
Received: 29 Nov. 2017
Accepted: 16 Feb. 2018
Published: 07 June 2018
code with your
sowart phone or
mobile device
to read online.
Kessler, V., 2018, 'God
becomes beautiful ... in
mathematics', HTS Teologiese
Studies/Theological Studies
74(1), 4886. https://doi.org/
10.4102/hts.v74i1.4886
Copyright:
C 2018. The Authors.
Licensee: AOSIS. This work
is licensed under the
Creative Commons
Attribution License.

This article is transdisciplinary in that it touches on the disciplines of both mathematics and theology. It is about the mysterious link between truth and beauty in mathematics. It uses the theological pattern laid by the practical theologian Bohren in his book, God's Becoming Beautiful. Mathematics can be seen as science or art. I argue that in both cases, we could conclude that God becomes beautiful in mathematics. This leads to the observation that there is some spirituality in mathematics. This insight might also have practical implications for mathematics education in schools.

\section{Introduction}

This article is transdisciplinary, touching on the disciplines of both mathematics and theology. It is about the striking links between the true, the good and the beautiful. A consideration of these issues leads to the following question: Does mathematics also have spiritual aspects? There have been some publications about spirituality in natural science, but only a few on spirituality in mathematics.

This article is also autobiographical. I write from the perspective of mathematics, which I studied initially, as well as from the perspective of theology, which I studied in my mid-30s. This article has a strong subjective component, as do the publications of the mathematicians Hardy ([1940] 2001), Hasse (1952) and Cassaza, Krantz and Ruden (2015). I do not claim to speak for the whole mathematical community, but I will give some evidence to demonstrate that my personal view is not uncommon among mathematicians.

Occasionally, the Bible draws links between the good and the beautiful. Often, the faith heroes of the Old Testament are also described as beautiful men or women, for example, Sarah (Gn 12:11, 14), Joseph (Gn 29:17), the child Moses (Ex 2:2), King David (1 Sm 16:18), Queen Esther (Es 2:7) and Daniel and his friends (Dn 1:6, 15). ${ }^{1}$ The passage on the Lord's Servant (Is 53:2-5) describes the ugliness of sin. In these instances, the Bible seems to draw a link between morality and aesthetics: he or she who is good in the ethical sense is also beautiful, and vice versa. Thus, we could almost propose an equation: 'beautiful $=($ morally) good'. But the Bible also reports on beautiful men and women who should not be regarded as faith models, such as King Saul (1 Sm 9:2), David's son Absalom (2 Sm 14:25) and the strange woman described in Proverbs (Pr 5:3). Proverbs 11:22 also discusses the case of a 'beautiful woman without discretion'. Thus, there are exceptions to the 'beautiful $=$ good' equation.

In mathematics, there is a striking correlation between truth and beauty; in other words, 'beautiful $=$ true' $^{2}$. This appears to suggest a mysterious link between epistemology and aesthetics. I will elaborate on this link below.

In this article, I walk in the footsteps of the practical theologian, Rudolf Bohren. Bohren (19202010) was of Swiss origin, but he spent most of his academic career in Germany, especially in Heidelberg. In his book, God's becoming beautiful (Dass Gott schön werde), Bohren (1975) lays the groundwork for his understanding of practical theology. At first glance we might be surprised by the title; after all, should it not read 'God is beautiful'? Bohren's approach is pneumatological (Bohren 1975:14). As the Holy Spirit is a recreator, a pneumatological practical theology must be future-oriented, looking at the new earth and the new city (p. 14). Practical theology reflects 'God's becoming practical', understood in the aesthetic sense of 'God's becoming beautiful' (p. 14). Thus, Bohren (1975:15) describes practical theology as 'theological aesthetics' (subtitle of his book), which has the task of shaping the world according to the laws of beauty. 'It is about the beautification 1.Interestingly, there are no such examples in the New Testament.

2.This connection is also expressed in the Latin proverb Pulchritudo splendour veritatis [Beauty is the splendour of truth] (Heisenberg 1971:102) 
of God in the midst of ... ugliness', as summarised by South African practical theologian Cilliers (2011:266). ${ }^{3}$ The Holy Spirit operates against the law of ugliness, which entered the world in the Fall (Bohren 1975:142-143). Bohren (1975:94-125) lists four areas where God becomes beautiful by the work of the Spirit of God: creation, culture and arts, history and the church.

I argue that we could also include mathematics in this list. Walking in the footsteps of Bohren, my thesis for this article is God becomes beautiful in mathematics. However, by saying this, I want to make it very clear that I do not subscribe to number mysticism - whether Jewish, Christian or otherwise motivated. Number mysticism does not convince me at all, neither as a mathematician nor as a theologian.

\section{My search for ... ... truth}

Mathematics has always fascinated me (and still does). My conversion to the Christian faith came much later. I opted for the study of mathematics because I was looking for eternal truths. I wanted to learn something that is true provably true - and I was fascinated by those insights that stayed true. In other disciplines, theories are often replaced by newer theories. Not so in mathematics. Thus, my search for eternal, provable truth led me quite naturally to the discipline of mathematics. I assume that this is typical of mathematicians. The German mathematician Helmut Hasse (1952:15) reported that even in his youth he was driven by the knowledge of objective, irrevocable valid truth, which outclassed every other interest. Cassaza et al. (2015:253-273) selected six essays under the headline 'Why I became a mathematician'. These essays show that my personal inclination is not unusual among mathematicians.

A similar drive led me to the study of theology. I was looking for eternal - even transcendental - truth. As a trained mathematician, I was inclined to apply the mathematical method to theology, and I regarded the Bible as an axiom system. (An axiom is a statement that is taken to be true.) Logical reasoning will then lead us to further propositions, based on this axiom system. In mathematical axiom systems, it is assumed that they do not lead to contradictions otherwise one mathematician might prove a proposition $A$ and another mathematician might prove the negation, non- $A$.

When I applied this mathematical approach to biblical exegesis, it had the following effect: Whenever I discovered propositions in the Bible that seemed to contradict one another, I tried to solve this contradiction. This was important for me because, as a mathematician, I cannot trust an axiom system that leads to contradictions.

Since then, I have discovered that the tensions in the Bible also have an appealing quality, bearing witness to the fact that the Bible is full of life. But this was a long journey for me.
Today I can see these tensions as 'creative tensions', a term that was programmatic for South African missiologist David Bosch (Kritzinger \& Saayman 1990).

\section{... beauty}

Retrospectively, I noticed that parallel to my search for truth, I also was searching for beauty. This connection became apparent to me while we, students, discussed the validity of a mathematical formula. Our mathematics professor then said: 'This formula cannot be true; it is just not beautiful enough'. He said this while winking, but this sentence contains a fundamental truth. In mathematics there is a remarkable striking link between beauty and truth.

People might argue that beauty is very subjective. I will not even try to define 'beauty'. Nor will I try to define 'truth'. Mathematicians simply believe in truth. They assume that there is a 'mathematical reality' (Hardy [1940] 2001:123) (the assumption of some postmodernists that truth is always relative is, for mathematicians, very suspicious and unbelievable). And many mathematicians believe in beauty as much as they believe in truth (see below). According to Dirac, mathematical beauty 'cannot be defined any more than beauty in art can be defined, but which people who study mathematics usually have no difficulty in appreciating' (in Chandrasekhar 1987:69).

I personally regarded pure mathematics as more elegant and beautiful than applied mathematics. Hence, I was more attracted to pure mathematics, and I completed my PhD in algebraic number theory.

Quotations from other mathematicians provide some evidence that my personal search for truth and beauty is quite typical of mathematicians. The famous mathematician Michael Atiyah (2015:29) says: 'Mathematics faces both ways: It is both art and science, and its practitioners serve two masters, Beauty and Truth'. A similar conclusion is drawn by Christiansen (2009:4): 'The only reasons to pursue the subject of mathematics is beauty and truth'.

Aschbacher (2015:18) is a spouse of a mathematician and, therefore, spends countless hours at dinners and conferences with mathematicians. She asked several of them why they were drawn to mathematics. A typical answer was that they were 'drawn towards it by its beauty and elegance'. The mathematicians she spoke to 'see beauty, wonder, harmony in the universe through mathematics and have a very aesthetic sense of it - something most non-mathematicians can't quite understand' (p. 18). Aschbacher (2015) mentions the following expressions made during a speech by a mathematician, who talked briefly about why he became a mathematician:

His reasons were 'the beauty of math' and the 'joy of algebraic geometry'. At the end of his talk, he thanked his wife of 28 years, who had given him the peace to do his research. (p. 28)

4.Actually, I am not aware of any convincing definition of 'truth'. Each attempt to define 'truth' already seems to presuppose an understanding of truth. 
'She let me do my research' is the best compliment a mathematician can offer to his wife.

\section{Beauty within mathematics}

This section is about the beauty within mathematics. Here I will not speak about how mathematics can contribute to the beauty of other areas, such as architecture, arts or music. In that regard, I refer you to books such as the one by Corbalán (2012) about the Golden Ratio, a mathematical language of beauty.

Aschbacher (2015:17) also put the following question to the mathematicians: 'Is math something like an unseen star, out there to be discovered (the Platonic view), or something we create to make sense of our world (Kantian view)?' Except for one case, she got the answer: 'Oh, it's definitely the "truths" of the world waiting to be discovered'. This attitude is also implicit in the mathematics parlance, as most mathematicians would say: 'I discovered this mathematical law'. The underlying assumption is that it was already there; it just needed to be brought to light. Hardy ([1940] 2001:123) shares this view: 'I believe that mathematical reality lies outside us, that our function is to discover or observe it'. Actually, the parlance changes when mathematicians speak of a certain algorithm. In these cases, they would say: 'He or she invented this algorithm'.

But there are some mathematicians who have a different view of this. The German mathematician Hasse calls Leibniz 'a creator of differential analysis', not only a discoverer. ${ }^{5} \mathrm{He}$ compares him with Beethoven, Goethe and Michelangelo, who created music, literature and visual arts, respectively. And the US mathematician Keith Devlin (2015:173) confesses to be 'no longer a Platonist', although he acknowledges that many mathematicians are Platonists.

\section{Mathematicians committed to beauty}

Several mathematicians feel committed to the beauty of mathematics. Plato (428/27-348/47 BC) was one of the first to speak about the link between mathematics and beauty (Heisenberg 1971:99). The famous astronomer Johannes Kepler (1571-1630) called mathematics 'the archetype of the beautiful' (in Chandrasekhar 1987:52). The German mathematician Karl Weierstrass (1815-1897) acknowledged that it is not possible to be a complete mathematician without being a bit of a poet. ${ }^{6}$ The French mathematician and theoretical physicist Henri Poincaré (1854-1912) wrote:

The Scientist does not study nature because it is useful to do so. He studies it because he takes pleasure in it; and he takes pleasure in it because it is beautiful. (Chandrasekhar 1987:59)

The German mathematician and theoretical physicist Hermann Weyl (1885-1955) is quoted by Dyson as saying:

5. Original quote: Ich sage absichtlich Schöpfer, nicht nur Entdecker (Hasse 1952:25).

6.Ein Mathematiker, der nicht etwas Poet ist, wird nie ein vollkommener Mathematiker sein (Brüning 2007:34). The translation of this quotation used by Atiyah (2015:30) is not completely correct.
'My work always tried to unite the true with the beautiful; but when I had to choose one or the other, I usually chose the beautiful' (in Chandrasekhar 1987:52). In 1907, the British mathematician and philosopher, Bertrand Russell (1872-1970), wrote: 'Mathematics, rightly viewed, possesses not only truth, but supreme beauty - a beauty cold and austere' (Russell [1907] 1959:60).

The famous physicist Albert Einstein (1879-1955) once wrote in the New York Times of 05 May 1935: 'Pure Mathematics is, in its way, the poetry of logical ideas' (in Brüning 2007). In 1939, the English theoretical physicist Paul Dirac (1902-1984) published an essay about the relationship between mathematics and physics in which he encouraged the research worker in physics to 'strive mainly for mathematical beauty' when he wants to express the fundamental laws of nature in mathematical form (Dirac 1939:123).

In 1940, the English mathematician GH Hardy (1877-1947) published an essay reflecting on his life as a mathematician and making a case for aesthetics in mathematics:?

The mathematician's patterns, like the painter's or the poet's, must be beautiful; the ideas, like the colours or the words, must fit together in a harmonious way. Beauty is the first test: there is no permanent place in the world for ugly mathematic. ... It may be very hard to define mathematical beauty, but that is just as true of beauty of any kind. (Hardy [1940] 2001:85)

The Austrian mathematician Emil Artin (1898-1962) is known for treating mathematics as art (in Borwein 2001:2). The German mathematician Helmut Hasse had studied with Artin. In his inaugural address at the University of Hambourg, Hasse (1952) spoke about 'mathematics as science, art and power'. There he denoted beauty as a leader to mathematical truth (p. 19). ${ }^{8}$ If a researcher is confronted with an unsolved problem, he should imagine how the formula would look if it were beautiful. Then this formula should be tested by examples, and, finally, the researcher will find the proof for this formula. According to Hasse (1952:26), truth is a necessary condition for real mathematics but is not sufficient. There must also be beauty and harmony (p. 26).

The above remarks hold for 'real mathematics' (Hardy [1940] 2001:119, 122), echte Mathematik (Hasse 1952:26). At school, mathematics is often presented as calculation rules and nothing more. This is not real mathematics in the sense that Hardy and Hasse used the term. Real mathematics began with the Greeks and their search for logical proofs.

A wonderful example of real mathematics is Euclid's proof that there must be infinitely many prime numbers. This proof can actually be taught at school level. It uses the interesting concept of an 'indirect proof', also called 'proof by contradiction' or reductio ad absurdum. To prove that there must be infinitely many prime numbers, we assume that the

\footnotetext{
7.There is some melancholy in this essay, firstly because Hardy ([1940] 2001:61) starts by acknowledging that he is too old to do mathematics and, secondly, because it was written during the Second World War (p. 140).
}

8.Actually, Hasse used the German word Führer. 
opposite was true, that is, there are only finitely many prime numbers. Then it is demonstrated that this assumption leads to a contradiction. Thus, the initial assumption cannot be true and there must be infinitely many prime numbers. ${ }^{9}$ Hardy ([1940] 2001:94) called the reductio ad absurdum 'one of the mathematician's finest weapons'. ${ }^{10}$

It should be noted that Hardy, Hasse and Artin were number theorists. Number theory is a very beautiful theory, which has been virtually useless for many centuries. Hardy loved this uselessness because number theory had 'no effects on war' (p. 140) (this statement is no longer valid because of the application of number theory in modern cryptography). Mathematical beauty might be less important to other mathematicians than it is to number theorists.

These days Sir Michael Atiyah (born 1929) is a popular speaker on beauty in mathematics (see Atiyah 1973; 2015; Roberts 2016). He also co-authored a paper with Zeki et al. (2014), theneurobiologist, whoinvestigated 16 mathematicians about how they experience mathematical beauty:

Results show that the experience of mathematical beauty correlates parametrically with activity in the same part of the emotional brain, ... as the experience of beauty derived from other sources. (p. 1)

\section{What does 'mathematical beauty' mean?}

What makes a mathematical theorem beautiful? The physicist Poincaré mentions 'simplicity and vastness' as criteria for beauty (in Chandrasekhar 1987:60). Heisenberg (1971:98) points to the coherence and simplicity of an axiom system, which makes us immediately think it is beautiful. ${ }^{11}$ The mathematician Hasse (1952:23) lists five criteria for mathematical beauty: clarity, transparency, conciseness, purposefulness and elegance. ${ }^{12}$

In my opinion, simplicity is a main criterion for mathematical beauty. ${ }^{13}$ The simpler a mathematical formula, the more beautiful it is. ${ }^{14}$ 'What could be simpler than $E=m c^{2}$ ?' is a rhetorical question that the French philosopher ComteSponville (2003:152) raised while investigating the virtue of simplicity. His link to Einstein's formula of the theory of relativity shows to which sort of simplicity he is referring. It is not about trivial simplicity, but about intelligent simplicity,

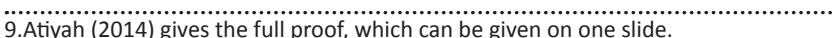
10.Hardy ([1940] 2001:94) supports this statement by drawing a parallel to chess: 'It is a far finer gambit than any chess gambit: a chess player may offer the sacrifice of a pawn or even a piece, but a mathematician offers the game'.

11.Original quote: Wir empfinden die Geschlossenheit und Einfachheit dieses Axiomensystems ohne jede Reflexion als schön (Heisenberg 1971:98).

12. He uses the German words Klarheit, Durchsichtigkeit. Prägnanz, Zielstrebigkeit, Eleganz.

13.The well-known saying 'simplex sigillum veri - the simple is the seal of the truth' is attributed to the Dutch botanist Herman Boerhaave (1668-1738). Note that Dirac (1939:123) argues that after the theory of relativity, the principle of simplicity must be replaced with the principle of beauty; thus for him, beauty does not necessarily include simplicity.

14.While pursuing my PhD in mathematics, the criterion of simplicity led me to the correct formula. I studied a concrete example, did the necessary computations and
suddenly I 'saw' the general formula that would fit into this example. Then I proved suddenly I 'saw' the general formula
this general formula (Kessler 1994). such as when research conducted over many years leads to a surprisingly simple formula. It is simple because it reduces complexity. This is actually how I define the virtue of simplicity: it means intelligent reduction of complexity (Kessler 2014). The criterion of simplicity can also be applied to the proof of a mathematical theorem. According to DeMillo, Lipton and Perlis (1979:274), simplicity is the first criterion that mathematicians tend to use when they check the validity of a proof.

In his short essay, Atiyah (1973) lists two criteria for mathematical beauty. Like a cathedral, which has both structural impressiveness and delicate details, 'a great mathematical theory should similarly be beautiful on both large and small scales' (Atiyah 1973:88). His second criterion is originality, that is, originality that surprises; and 'the grandest surprise ... are the unexpected links between apparently quite different parts of mathematics' (p. 88).

Hardy ([1940] 2001:113) also lists the surprise effect as an aesthetic criterion: 'a very high degree of unexpectedness, combined with inevitability and economy'. In addition, 'the beauty of a mathematical theorem depends a great deal on its seriousness' (p. 90). Seriousness means that many different mathematical ideas are connected in the theorem (p. 89).

Atiyah (2014) lists six criteria for mathematical beauty: elegance, clarity, simplicity (controlling complexity), originality, depth and importance. This list seems to be a good summary of the discussion above.

Now, let us have a look at the most beautiful mathematical formula to illustrate these criteria.

\section{The most beautiful formula in mathematics}

The 'beauty competition' held by Zeki et al. delivered a clear winner. The participants, 16 mathematicians, were given 60 mathematical formulae to rate on a scale of -5 (ugly) to +5 (beautiful) the beauty of each formula (Zeki et al. 2014:2). The winner was the so-called Euler's identity (p. 4):

$e^{i \pi}+1=0$

[Eqn 1]

This can be attributed to the Swiss mathematician Leonhard Euler (1707-1783), and it contains exactly five numbers: 0, 1, $\pi, e$ and $i$. Each of these numbers is a very important number (VIN) from a mathematical point of view. The beauty of Euler's identity lies in the fact that it combines five VINs in the simplest way, that is, without any non-VIN:

1. The number 0 is the neutral element of addition ('add 0 and nothing happens').

2. The number 1 is the neutral element of multiplication ('multiply with 1 and nothing happens').

3. The number $\pi=3.14159 \ldots$ has been introduced as the ratio of a circle's circumference to its diameter ${ }^{15}$ : circumference $=\pi \times$ diameter.

15.The builders of the temple in Jerusalem worked with the approximation 3 (which was also common in Babylonia). According to 1 Kings 7:23, the sea of cast metal had a diameter of 10 cubits and a circumference of 30 cubits. 
4. The number $e$, sometimes called Euler's number, is the basis of the natural logarithm. Its first digits are given by $e=2.71828 \ldots$ It is one of the most important mathematical constants; for example, it is needed for calculating growth of populations or growth of interest.

5. The imaginary unit $i$ is defined by the property $i^{2}=-1$, leading to complex numbers.

The mathematical constants $\pi$ and $e$ are interesting numbers, each of them appearing in many different mathematical theories or applications. Many books have been written on them, but they are also difficult numbers: both are irrational and even transcendent. ${ }^{16}$ But at least both are real numbers, whereas the imaginary unit $i$ is not a real number. Raising $e$ to $\pi$ leads to the following:

$e^{\pi}=23.14069$.

Thus, it comes as a surprise that raising $e$ to the product $(i \pi)$ leads to a very simple result:

$e^{i \pi}=-1$,

which is just a re-statement of $e^{i \pi}+1=0$. Euler's identity is regarded as a beautiful formula because, firstly, it is very simple; secondly, it combines five different VINs; and, thirdly, it comes as a surprise.

Despite the enthusiasm for the beauty within mathematics and the mysterious link between mathematical beauty and mathematical truth, it should also be noted that an ugly formula is not necessarily false. In Zeki's study, it was found that the majority of the participating mathematicians rated a given formula as ugly, even though it was a valid one (Zeki et al. 2014:4).

\section{Spirituality in mathematics}

The beauty of mathematics gives those who are responsive to it something for the heart and the soul (Hasse 1952:15). Sometimes it triggers emotions or experiences, which can be seen as spiritual experiences or at least close to. Listen to the words of the atheist Russell ([1907] 1959):

The true spirit of delight, the exaltation, the sense of being more than man, which is the touchstone of the highest excellence, is to be found in mathematics as surely as in poetry. (p. 60)

Russell's emotions look a bit similar to the emotions, which were called mysterium tremendum by the German systematic theologian Rudolf Otto (1869-1937) in his famous book, The Idea of the Holy (Otto 1936:12). This mysterium tremendum contains elements of awfulness and overpoweringness (majestas) (pp. 14, 20). The German physicist Heisenberg once said to his colleague, Einstein:

You must have felt this too: the almost frightening simplicity and wholeness of the relationships which nature suddenly spreads out before us and for which none of us was in the least prepared. (Chandrasekhar 1987:53)

16.A number is described as 'transcendent' if there is no algebraic equation with rational numbers, so that this number would solve this algebraic equation. The transcendence of $\pi$ and $e$ were proved in the 19th century.
The mathematician Watson spent several years with the famous Indian mathematician Ramanujan (1887-1920) and later reported that a special mathematical formula from Ramanujan 'gives me a thrill which is indistinguishable from the thrill which I feel when I enter the Sagrestia Nuova of Capelle Medicee and see before me the austere beauty' of Michelangelo's art works (in Chandrasekhar 1987:61). Chandrasekhar (1987:54) calls it the 'shuddering before the beautiful'.

The US scholar Witz (2007) conducted an interesting study on the spiritual aspirations related to mathematics. This book provides six very vivid and in-depth portraits of individual students of mathematics. Witz (n.d.:3) quotes a mathematician, saying: 'You know, Klaus, Mathematics is a religion'. In a book review, Christiansen (2009:6) concludes: 'A spiritual element in mathematics may be the reason that many find gratification in the subject - something that one may find in mathematics, and not in any other subject'.

Two of the participants in Witz's study, both PhD students in mathematics, even speak about 'epiphanies' in the context of mathematics (Witz 2007:211ff., 252ff.). One of them used to be a non-practising Catholic, but he had a revelation while studying mathematics. He later returned to Catholicism and now regards mathematics as 'sacred activities' because 'math is uncovering the nature of Christ' (p. 231). This student connects his spiritual experience within mathematics with the Christian faith. 'I know that the pattern of the universe is Christ and that is the center of my faith' (p. 231).

Other mathematicians might connect their spiritual experiences with other religions or with no religion at all. But some personal accounts from Cassaza et al. (2015) show links between spirituality and mathematics, even if the author would just use the language of religion or spirituality as Boas (2015:256) did: 'After sitting at the feet of these gurus for a year, I was a lifelong convert to the religion of mathematics'.

It would be an interesting research topic to investigate the spirituality in mathematics in greater detail in order to explore the following question: What is it that a person seems to find in mathematics, but not in any other subject?

\section{Conclusion}

1. In mathematics, we find a remarkable correlation between truth and beauty. The Bible testifies to the correlation between ethics and beauty. But in both cases, there are possible exceptions: ugly mathematical formulae that are nevertheless true and physically beautiful men and women who do bad things.

2. Mathematicians such as Hardy, Artin, Hasse and Atiyah regard mathematics as both art and science. This is exactly how Bohren (1975:191) sees practical theology. In the chapter entitled 'Practical theology as art and science', he quotes Karl Barth (1962) about the aesthetics of systematic theology (Bohren 1975:197). 
3. Mathematicians disagree about whether mathematical theories are created or discovered. The majority of mathematicians regard mathematical reality as something outside of us. If we share this view, we could argue: Every time a mathematician discovers a beautiful formula, they discover something that God created. Thus, the mathematician contributes to the visibility of God's beauty in his creation. This would correspond with Bohren's viewpoint that God becomes beautiful in the creation (Bohren 1975:94-99). If, however, we follow the minority's viewpoint, namely that mathematics is a creation, then it would correspond with Bohren's chapter 'Culture and arts'. In that chapter, Bohren (1975:100) argues that God becomes beautiful by and through human creations in culture and arts. Thus, in both cases, we can conclude: God becomes beautiful in mathematics. This conclusion may be reached, whether a mathematician believes in God or not. Bohren (1975:105) stresses that God also becomes beautiful through those who do not know Him. For example, Russell and Hardy, two mathematicians often quoted in this essay, were selfconfessed atheists. Nevertheless, Bohren would argue that God became beautiful in their mathematical work. Even the French reformer John Calvin (1509-1564), who used to distinguish clearly between Christians and non-Christians, taught that the Spirit of God might even work through ungodly mathematicians:

If we reflect that the Spirit of God is the only fountain of truth, we will be careful, as we would avoid offering insult to him, not to reject or condemn truth wherever it appears. In despising the gift we insult the Giver. ... But if the Lord has been pleased to assist us by the work and ministry of the ungodly in physics, dialectics, mathematics, and other similar sciences ... (Institutio II.2.15-16)

Therefore, I trust that there is now enough evidence for my initial statement: God becomes beautiful in mathematics:

4. One might critically remark that, for some, mathematics has become a substitute for Christianity, even constituting a religion in its own right. As these mathematicians enjoy spiritual experiences while doing mathematics, they might not need to look for spirituality elsewhere. It is a well-known temptation to forget about the creator if the beauty of the creation is so fascinating. But this does not belie the fact that God becomes beautiful in mathematics.

5. There has been very little research on spirituality in mathematics. Nevertheless, there are some known examples where mathematicians have reported spiritual experiences while doing mathematics, and it would be interesting to follow up on these. It would also be useful to ask the following questions: What is the special element in mathematics that cannot be found in any other subject? And how can we categorise the spiritual experiences in mathematics?

6. After reading this article at UNISA, ${ }^{17}$ a professor of mathematical education mentioned to me that, in their school education, the spiritual aspects of mathematics

17.14 November 2017, at the invitation of Prof. Christo Lombaard, Department of Christian Spirituality, Church History and Missiology. would not even be considered. Yet she believes that demonstrating the beauty of mathematics might be the key to highlighting the spiritual aspects of mathematics, which might foster more enthusiasm for the subject on the part of the students.

7. I hope that this paper will not only be regarded as a contribution to truth, but that it might also contribute to beauty itself. As quoted above, one criterion of beauty in mathematics is 'the unexpected links between apparently quite different parts of mathematics' (Atiyah 1973:88). So, perhaps, some readers of this article will recognise beauty in the fact that this transdisciplinary article reveals some unexpected links between different academic disciplines.

\section{Acknowledgements Competing interests}

The author declares that he or she has no financial or personal relationships which may have inappropriately influenced him or her in writing this article.

\section{References}

Aschbacher, P., 2015, 'What are mathematicians really like? Observations of a spouse', in P. Cassaza, S.G. Krantz \& R.D. Ruden (eds.), I, Mathematician, pp. 16-28, The Mathematical Association of America, Washington, DC.

Atiyah, M., 1973, 'Mathematics: Art and science', Bulletin of the American Mathematical Society 43(1), 87-88. https://doi.org/10.1090/S0273-0979-05-01095-5

Atiyah, M., 2014, Beauty of mathematics, Lecture at University of Edinburgh, viewed 18 August 2017, from dailymotion.com

Atiyah, M., 2015, 'Mathematics: Art and science', in P. Cassaza, S.G. Krantz \& R.D. Ruden (eds.), I, Mathematician, pp. 29-30, The Mathematical Association of America, Washington, DC.

Barth, K., 1962, Einführung in die evangelische Theologie, TVZ, Zürich.

Boas, H.P., 2015, 'Why I became a mathematician: A personal account', in P. Cassaza, S.G. Krantz \& R.D. Ruden (eds.), I, Mathematician, pp. 255-256, The Mathematical Association of America, Washington, DC.

Bohren, R., 1975, Daß Gott schön werde: Praktische Theologie als theologische Ästhetik, Chr. Kaiser, München.

Borwein, J., 2001, 'Aesthetics for the working mathematician', in Queens University Symposium on Beauty and the Mathematical Beast: Mathematics and Aesthetics, April 18, viewed 19 June 2017, from wayback.cecm.sfu.ca

Brüning, J., 2007, 'Die Fläche des Poeten', Mitteilungen der deutschen MathematikerVereinigung 15, 33-36. https://doi.org/10.1515/dmvm-2007-0014

Calvin, J., 1845, The Institute of the Christian Faith, Christian Classics Ethereal Library, Grand Rapids, MI, viewed 09 November 2017, from ccel.org

Cassaza, P., Krantz, S.G. \& Ruden, R.D. (eds.), 2015, I, Mathematician, The Mathematical Association of America, Washington, DC.

Chandrasekhar, S., 1987, Truth and beauty: Aesthetics and motivations in science, Chicago University Press, Chicago, IL.

Christiansen, A., 2009, 'The beauty and spirituality of mathematics: A review essay', International Journal of Education \& the Arts 10 (Review 2), viewed 18 August 2017, from www.ijea.org/v10r2

Cilliers, J., 2011, 'Fides quarens pulchrum: Practical theological perspectives on the desire of beauty', Scriptura 108(3), 267-266.

Comte-Sponville, A., 2003, A short treatise on the great virtues. The uses of philosophy in everyday life, Vintage, London.

Corbalán, F., 2012, The golden ratio. The beautiful language of mathematics, RBA Coleccionables, London.

DeMillo, R., Lipton, R.J. \& Perlis, A.J., 1979, 'Social processes and proofs of theorems and programs', Communications of the ACM 22(5), 271-280. https://doi.org/ and programs, Commun

Devlin, K., 2015, 'The badly taught high school calculus lesson and the mathematical journey it led me to', in P. Cassaza, S.G. Krantz \& R.D. Ruden (eds.), I, Mathematician, pp. 169-182, The Mathematical Association of America, Washington, DC.

Dirac, P., 1939, 'The relation between mathematics and physics', in Proceedings of the Royal Society Edinburgh, vol. 59, Part II, pp. 122-129, viewed 08 November 2017, from damtp.cam.ac.uk

Hardy, G.H., [1940] 2001, A mathematician's apology, Cambridge University Press, Cambridge.

Hasse, H., 1952, Mathematik als Wissenschaft, Kunst und Macht, Verlag für Angewandte Wissenschaften, Wiesbaden. 
Heisenberg, W. 1971, 'Die Bedeutung des Schönen in der exakten Naturwissenschaft', Physikalische Blätter 27(3), 97-197. https://doi.org/10.1002/phbl.19710270301

Heitink, G., 1999, Practical theology: History, theory, action domains, Wm. B. Eerdmans, Grand Rapids, MI.

Kessler, V., 1994, 'Crossed product orders and non-commutative arithmetic', Journal of Number Theory 46(3), 255-302. https://doi.org/10.1006/jnth.1994.1015

Kessler, V., 2014, 'Einfachheit (Komplexitätsreduktion)', in H. Afflerbach, R. Kaemper \& V. Kessler (eds.), Lust auf gutes Leben. 15 Tugenden neu entdeckt, pp. 109-115, Brunnen, Gießen.

Kritzinger, J.N.J. \& Saayman, W. (eds.), 1990, Mission in creative tension: A dialogue with David Bosch, S.A. Missiological Society, Pretoria.

Otto, R., 1936, The idea of the Holy. An inquiry into the non-rational factor in the idea of the divine and its relation to the rational, Oxford University Press, Oxford.
Roberts, S., 2016, 'Michael Atiyah's imaginative state of mind', Quantamagazine, viewed 16 June 2017, from www.quantamagazine.org/michael atiyahsmathematical-dreams-20160303.

Russell, B., [1907] 1959, 'The study of mathematics', New Quarterly 1, 29-44. Reprinted in Russell, B., 1959, Mysticism and logic: And other essays, 11th edn., pp. 58-73, George Allen, London.

Witz, K.G., 2007, Spiritual aspirations connected with mathematics. The experience of American university students, Edwin Mellen Press, Lewiston, ME.

Witz, K.G., n.d., 'Spiritual aspirations connected with mathematics. The experience of American university students', viewed 06 October 2017, from www.socialsciences. exeter.ac.uk

Zeki, S., Romaya, J.P., Benincasa, D.M. \& Atiyah, M.F., 2014, 'The experience of mathematical beauty and its neural correlates', Frontiers in Human Neuroscience 8(68), 1-12. https://doi.org/10.3389/fnhum.2014.00068 